\title{
Characteristics of Control Laws Tested on the Semi-Span Super-Sonic Transport $\left(\mathrm{S}^{4} \mathbf{T}\right)$ Wind-Tunnel Model
}

\author{
David M. Christhilf * \\ Lockheed Martin Engineering \& Sciences, Inc., Hampton, VA, 23681-2199 \\ Boris Moulin ${ }^{\dagger}$, Erich Ritz ${ }^{\star}$, P. C. Chen ${ }^{\S}$ \\ ZONA Technology, Inc., Scottsdale, AZ 85258-4578 \\ Kevin M. Roughen" \\ M4 Engineering, Inc., Long Beach, CA, 90755-3517 \\ and \\ Boyd Perry III $^{\#}$ \\ NASA-Langley Research Center, Hampton, VA, 23681-2199
}

\begin{abstract}
The Semi-Span Supersonic Transport $\left(S^{4} T\right)$ is an aeroelastically scaled wind-tunnel model built to test active controls concepts for large flexible supersonic aircraft in the transonic flight regime. It is one of several models constructed in the 1990's as part of the High Speed Research (HSR) Program. Control laws were developed for the $\mathrm{S}^{4} \mathrm{~T}$ by M4 Engineering, Inc. and by Zona Technologies, Inc. under NASA Research Announcement (NRA) contracts. The model was tested in the NASA-Langley Transonic Dynamics Tunnel (TDT) four times from 2007 to 2010 . The first two tests were primarily for plant identification. The third entry was used for testing control laws for Ride Quality Enhancement, Gust Load Alleviation, and Flutter Suppression. Whereas the third entry only tested FS subcritically, the fourth test demonstrated closed-loop operation above the open-loop flutter boundary. The results of the third entry are reported elsewhere. This paper reports on flutter suppression results from the fourth wind-tunnel test. Flutter suppression is seen as a way to provide stability margins while flying at transonic flight conditions without penalizing the primary supersonic cruise design condition. An account is given for how Controller Performance Evaluation (CPE) singular value plots were interpreted with regard to progressing open- or closed-loop to higher dynamic pressures during testing.
\end{abstract}

\section{Nomenclature}

$\mathrm{M}=$ Mach Number, nondimensional

$\overline{\mathrm{q}}=$ Dynamic Pressure, $\mathrm{lb} / \mathrm{ft}^{2}$

$\rho=\quad=$ Fluid Density, $\mathrm{sl} / \mathrm{ft}^{3}$

$V \quad=$ Fluid Velocity, $\mathrm{ft} / \mathrm{s}$

$\zeta=$ Modal Damping, nondimensional

$\mathrm{g}=$ Structural Damping $(\mathrm{g}=2 \boldsymbol{\zeta})$, nondimensional

$\delta_{c} \quad=$ Commanded Control Deflection, deg

$\delta=$ Control Position, deg

$\sigma \quad=$ White Noise, nondimensional

$w_{g} \quad=$ Vertical Gust Rate, $\mathrm{ft} / \mathrm{s}$

$\mathrm{F}_{\mathrm{f}}, \mathrm{F}_{4}=$ Flutter Frequency, Hz, for Primary Flutter Mode and for Mode 4

$\mathrm{Q}_{\mathrm{f}}, \mathrm{Q}_{4}=$ Flutter Dynamic Pressure, $\mathrm{lb} / \mathrm{ft}^{2}$, for Primary Flutter Mode and for Mode 4

\footnotetext{
* Research Engineer Staff, Langley Program Office, c/o NASA-LaRC, Mail Stop 308, AIAA Senior Member.

${ }^{\dagger}$ Control Engineering Specialist, 9489 E. Ironwood Square Drive, AIAA Member.

* Aerostructural Engineer, 9489 E. Ironwood Square Drive, AIAA Member

$\S$ President, 9489 E. Ironwood Square Drive, AIAA Associate Fellow.

"Vice President of Engineering, 4020 Long Beach Blvd., AIAA Member.

${ }^{\#}$ Assistant Branch Head, Aeroelasticity Branch, AIAA Senior Member.
} 


\section{Introduction}

$\mathrm{T}$ HE Semi-Span Super-Sonic Transport $\left(\mathrm{S}^{4} \mathrm{~T}\right)^{1-3}$ aeroelastically scaled wind-tunnel model (Fig. 1) is one of several models constructed in the 1990's as part of the High Speed Research (HSR) program. It represents the Technology Concept Aircraft (TCA) configuration, and is representative of a class of vehicles with a long, slender fuselage and a thin, swept wing. For aircraft of this class, flexibility must be taken into account in the design for static deformation, airframe dynamic response to disturbances, and aeroelastic stability. Aeroelastic tailoring can be used to make efficient use of the structural materials, but generally there is a trade-off between stiffness and strength on the one hand, and weight on the other. When stiffness is compromised due to the need to reduce weight, the symptoms can manifest themselves in terms of increased dynamic response to turbulence that adversely impacts ride quality for the passengers and possibly the flying qualities for the pilot. ${ }^{4}$ In extreme cases, the airflow may interact with the airframe in such a way that energy is continuously transferred from the flow to the airframe, resulting in flutter. Reduced stiffness and strength may also reduce airframe fatigue life in response to unsteady loads experienced in the presence of turbulence.

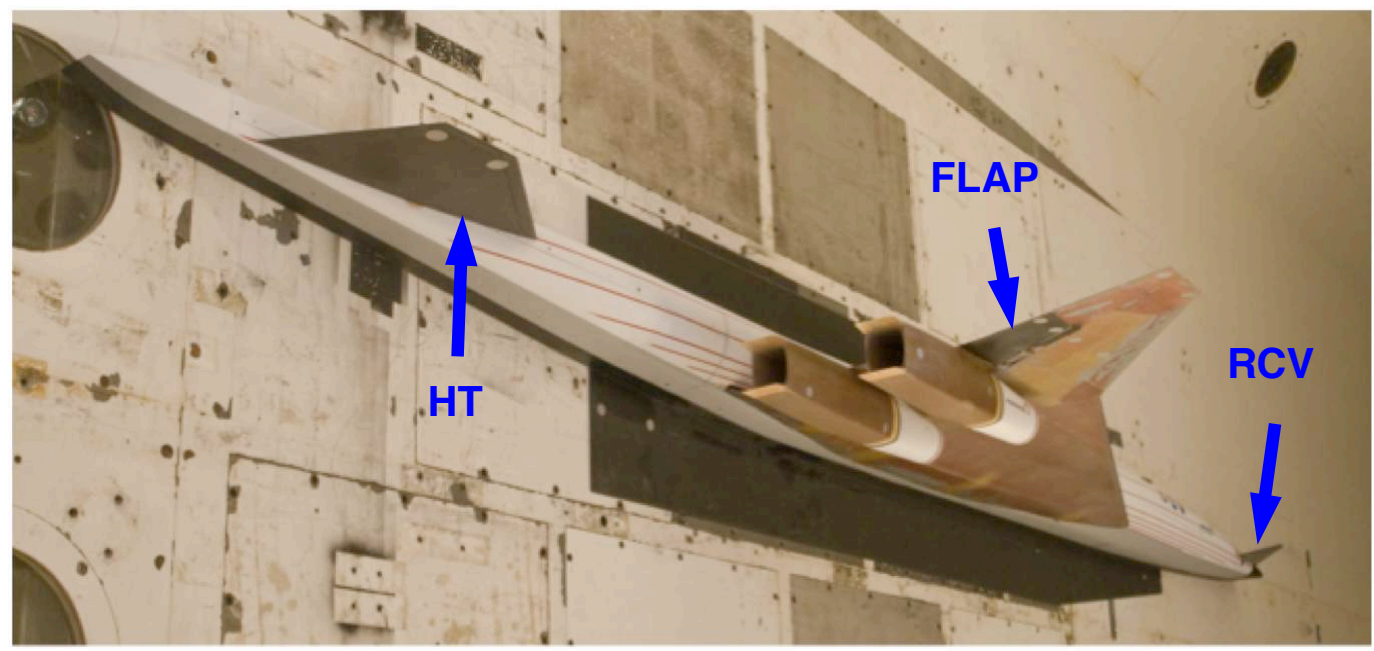

Figure 1. $\quad \mathbf{S}^{4} \mathbf{T}$ In Wind-Tunnel. Aft view of wing, engine nacelles, aerodynamic fairing, allmoving horizontal tail (HT), wing trailing edge control surface (FLAP), and ride control vane $(R C V)$.

Achieving a successful design can be particularly challenging for a large, flexible vehicle constructed of anisotropic composite materials that must transition through the transonic regime with local, possibly intermittent, shocks while carrying passengers. One potential means of addressing these concerns without adding substantial weight is through the use of active controls to effectively add artificial damping through feedback. The payoff is enhanced by consideration that once cruise conditions are achieved at around $60,000 \mathrm{ft}$ altitude, the turbulence is reduced. Furthermore the supersonic cruise condition (Mach number 2.4 for the TCA) is significantly less prone to flutter than the transonic flight regime. Therefore if the design margins required for subsonic cruise over land and for transition through the lower altitude and transonic regimes can be provided through active controls, the design for the long-duration cruise portion of the flight does not need to be compromised as much by other design conditions.

The $\mathrm{S}^{4} \mathrm{~T}$ wind-tunnel model was designed for testing with active controls in the NASA-Langley Transonic Dynamics Tunnel (TDT), and was constructed with three hydraulically actuated control surfaces and multiple accelerometers and strain gauges. ${ }^{5}$ A diagram depicting the location of the control surfaces and sensors is shown in Fig. 2. The control surfaces are the horizontal all-moving Ride Control Vane (RCV) located near the pilot station, the single wing-trailing-edge control surface (FLAP) located just outboard of the nacelles, and the all-moving Horizontal Tail (HT). The $\mathrm{S}^{4} \mathrm{~T}$ was tested open-loop during tunnel entries in 2007 and 2008, and closed-loop during tunnel entries in 2009 and $2010^{*}$.

\footnotetext{
* Specifically tests T597, T600, T608 and T616.
} 
Three types of control laws were developed and tested: Ride Quality Enhancement (RQE), Gust Load Alleviation (GLA), and Flutter Suppression (FS). Analytical models of the $\mathrm{S}^{4} \mathrm{~T}$ (plant) and control laws for testing on the $\mathrm{S}^{4} \mathrm{~T}$ were developed under NASA Research Announcement (NRA) contracts with M4 Engineering, Inc. of Long Beach, California, and ZONA Technology Inc. of Scottsdale, Arizona. An FS control law and a Simulink simulation of the $\mathrm{S}^{4} \mathrm{~T}^{6}$ that incorporated the plant models and control laws were developed by Lockheed Martin (LM) under the Technology Engineering and Aerospace Mission Support (TEAMS) contract onsite at NASALangley in Hampton, Virginia. Plant models were also developed by NASA. ${ }^{7}$

The state-space plant models were generated using a NASTRAN structural Finite Element Model (FEM) as well as several methods for calculating the unsteady Generalized Aerodynamic Forces (GAF's) ${ }^{8}{ }^{80}$ For some of the models, modifications were made to the FEM to adjust wind-off frequencies to better match $\mathrm{S}^{4} \mathrm{~T}$ experimental data. ${ }^{11}$ These linear state-space models were used for control law design. Metrics were established for design and evaluation of each type of control law (RQE, GLA, FS). The following sections provide plant characteristics of interest for control law design, and characterize the several methods used for control law design, the sensors, control surfaces, and number of state variables used for each control law, and the tunnel conditions for which each control law was tested during the fourth wind-tunnel entry that probed the open-loop flutter boundary. Results from the third wind-tunnel test for the RQE and GLA metrics have been published previously. ${ }^{12,13}$

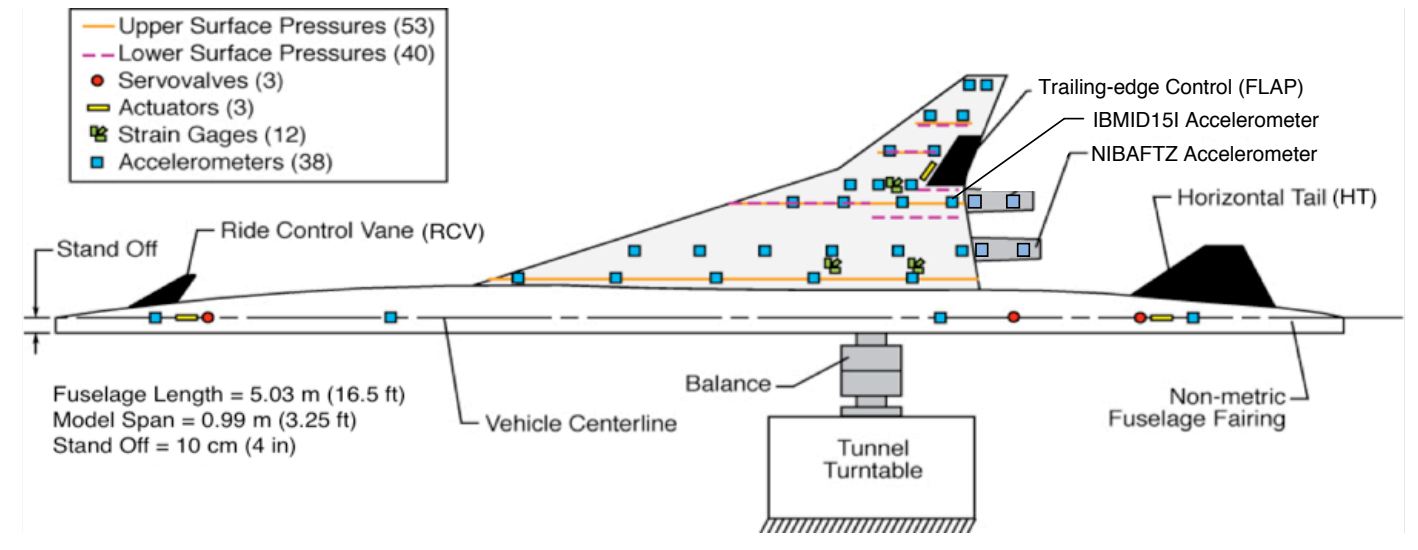

Figure 2. Instrumentation Layout. General depiction of mount system, wing, engine nacelles, fuselage fairing, control surfaces, accelerometers, and strain gauges.

\section{Plant Models Used for Control Law Design}

The $\mathrm{S}^{4} \mathrm{~T}$ had two configurations: non-ballasted and ballasted. The ballasted configuration added mass to the engine nacelles and reduced the stiffness of the engine mounts in order to produce flutter onset within the test envelope of the TDT. ZONA determined that the ballasted and non-ballasted configurations had two different flutter mechanisms, and they developed control laws for both. The non-ballasted configuration was tested open-loop in the first two wind tunnel tests, but was never tested with a control law. Results reported here are for the ballasted configuration only.

The $\mathrm{S}^{4} \mathrm{~T}$ mounting system was designed to interfere with the vehicle flexure as little as possible, given that the model would be mounted to the wall of a wind tunnel. Fuselage flexibility was represented by a flexible beam inside a "quasirigid" aerodynamic fairing. The RCV and HT control surfaces and the aeroelastically scaled wing were mounted to the beam, which in turn was supported by spring mounts with additional mechanisms used to restrict the roll degree-of-freedom. The fuselage supports transferred forces and moments to a load balance mounted to the wall, whereas the fuselage fairing loads bypassed the load balance. The clearances for the spring supports accommodated a limited amount of travel similar to pitch and plunge rigid body modes, but with artificial restoring forces at the spring locations. Although the airflow in the test section can be represented with a plane of symmetry for the tunnel wall, and the motion allowed by the support system was more characteristically symmetric than antisymmetric, no plane of symmetry was assumed for the structural models.

Angle-of-attack was not an input to the linear models, even for the transonic case. The angle-of-attack for the wind-tunnel model and the steady bias commanded for each control surface were adjusted to "fly" the model off the lower range of travel for the springs such that the wing and the shafts for the HT and RCV would not contact the 
(non-metric) aerodynamic fairing. As a result, the range in angle-of-attack changed with dynamic pressure but followed a fairly restricted corridor, although some variation in angle-of-attack was permitted.

\section{A. Analytical Plant Models - Root Locus}

Prior to the third and fourth wind tunnel tests, a decision was made to restrict testing to three Mach numbers that span the subsonic/transonic/supersonic transition, namely $\{0.8,0.95,1.1\}$. The TDT uses a (subatmospheric) variable pressure heavy gas as a test medium in order to achieve proper aeroelastic mass scaling and to be able to decouple changes in Mach number $(M)$ from changes in dynamic pressure $(\overline{\mathrm{q}})$. The test plan that was adhered to was to arrive at a specified Mach number at a low fluid density and low dynamic pressure, and then to increase $\overline{\mathrm{q}}$ at constant $\mathrm{M}$ by bleeding in more heavy gas. Although that procedure increases $\overline{\mathrm{q}}$ more slowly than changing tunnel flow rate would, it permitted probing potential flutter conditions without having the additional concern of encountering a change in flow character due to a change in Mach number. Consistent with the test plan, analytical models were generated for the three Mach numbers and spanning a range of dynamic pressure from below to above the open-loop flutter boundary.

Five types of analytical models will be discussed. They are the Doublet Lattice Method (DLM) and the Wind Tunnel Based (WTB) models developed by M4 Engineering, Inc., the Finite Element Analysis (FEA) models developed by NASA, and the ZONA Aerodynamics (ZAERO) and ZONA Euler Unsteady Solver (ZEUS) models developed by ZONA Technology, Inc.

A dynamic pressure root locus is shown in Fig. 3 for the FEA plant model for $\mathrm{M}=0.95$ and a range of $\overline{\mathrm{q}}$ from 0 to $250 \mathrm{lb} / \mathrm{ft}^{2}$ at increments of $5 \mathrm{lb} / \mathrm{ft}^{2}$. The FEA model has 30 second-order structural modes, with 4 aerodynamic lag terms per mode, for a total of 180 state variables. Eigenvalues for only the first 8 (complex) structural modes are show in the figure, since they illustrate the flutter mechanism involving modes 1 and 2 . The axes are normalized by $(2 \pi)$ so that the vertical axis represents $\mathrm{Hz}$ rather that $\mathrm{rad} / \mathrm{s}$. The $\overline{\mathrm{q}}=0 \mathrm{lb} / \mathrm{ft}^{2}$ points on the locus are marked with $\times$, whereas the $\overline{\mathrm{q}}=250 \mathrm{lb} / \mathrm{ft}^{2}$ points are marked with *. The assumed modal damping for $\overline{\mathrm{q}}=0$ for the FEA model was $\xi=0.25 \%$, or equivalently a structural damping of $\mathrm{g}=0.5 \%$. Although details of

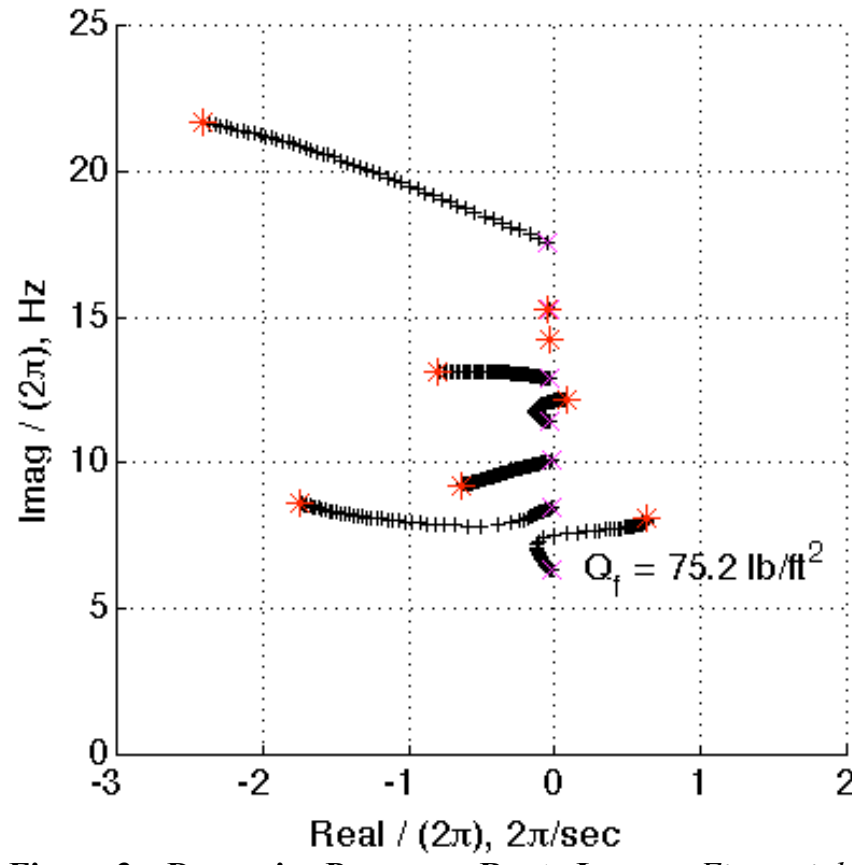

Figure 3. Dynamic Pressure Root Locus. First eight structural modes, at Mach number 0.95 for a range of dynamic pressure from 0 to $250 \mathrm{lb} / \mathrm{ft}^{2}$ for FEA model. modeling the unsteady aerodynamics vary considerably with Mach number and from model to model, the general topology of the first 8 modes is similar for all cases, starting with a common structural model for the $\overline{\mathrm{q}}=0 \mathrm{lb} / \mathrm{ft}^{2}$ condition with the following exceptions. The assumed modal damping for the DLM, WTB, ZAERO and ZEUS models was nominally $\zeta=\{1.0,1.0,1.54,1.54\}$ percent, respectively. For the WTB model, adjustments were made to the finite element model in order to modify the frequency and damping for certain structural modes to match results from $\mathrm{S}^{4} \mathrm{~T}$ Ground Vibration Tests (GVT's) in an effort to improve the fidelity of the WTB analytical model relative to the DLM model.

The primary flutter mechanism involves modes 1 and 2 coalescing in frequency, with one of the two migrating to the right half plane indicating transition to negative damping (instability) for that mode. For the transonic case shown here, the lower frequency mode 1 is the one which becomes unstable at flutter dynamic pressure $\left(\mathrm{Q}_{\mathrm{f}}\right)$ equal to $75.2 \mathrm{lb} / \mathrm{ft}^{2}$, but for FEA models at $\mathrm{M}=\{0.6,0.8,0.9,1.1,1.2\}$, the higher frequency mode 2 goes unstable. The flutter frequency $\left(\mathrm{F}_{\mathrm{f}}\right)$ is defined as the frequency of the flutter mode as it crosses the imaginary axis. Above the open-loop flutter dynamic pressure the frequency of the flutter mode is observed in Fig. 4 to increase slightly with increasing $\overline{\mathrm{q}}$. It is evident in the figure that mode 4 has the potential to go unstable at a dynamic pressure higher than $\mathrm{Q}_{\mathrm{f}}$ if the primary flutter mode is stabilized using feedback, or at a lower dynamic pressure if the feedback control law is improperly designed. The potential for mode- 4 instability is less pronounced in the analytical models for subsonic 
and supersonic conditions. Table 1 shows the value for $\mathrm{Q}_{\mathrm{f}}$ for the various analytical models, as well as the dynamic pressure $\mathrm{Q}_{4}$ for which mode 4 goes unstable for some of the models. For the Mach number 0.95 condition, two of the three available models indicate that mode 1 was the critical mode, as shown in the table. Items in darker shading indicate conditions that were tested in the wind tunnel.

The flutter dynamic pressures and frequencies in Table 1 were estimated from the available plant models using one of two techniques. For the FEA, ZAERO and ZEUS models, an interval was found for which the model at one dynamic pressure was stable and the model for the next available higher dynamic pressure case had an unstable complex mode. The state-space matrices were then interpolated using a parameter representing dynamic pressure, and an iterative procedure was used to find a model for which the

Table 1. Properties of Analytical Models

\begin{tabular}{|c|c|c|c|c|c|c|c|}
\hline Model & $\begin{array}{c}\text { Mach } \\
\text { Number }\end{array}$ & $\begin{array}{c}\text { Damping } \\
\zeta\end{array}$ & $\begin{array}{c}\text { Flutter } \\
\text { Mode }\end{array}$ & $\begin{array}{c}\text { Flutter } \\
\mathrm{Q}_{\mathrm{f}}, \mathrm{lb} / \mathrm{ft}^{2}\end{array}$ & $\begin{array}{c}\text { Flutter } \\
\mathrm{F}_{\mathrm{f}}, \mathrm{Hz}\end{array}$ & $\begin{array}{c}\text { Mode 4 } \\
\mathrm{Q}_{4}, \mathrm{lb} / \mathrm{ft}^{2}\end{array}$ & $\begin{array}{c}\text { Mode 4 } \\
\mathrm{F}_{4}, \mathrm{~Hz}\end{array}$ \\
\hline DLM & 0.6 & 0.01 & 2 & 84.6 & 7.33 & $>350$ & --- \\
DLM & 0.8 & 0.01 & 2 & 80.4 & 7.19 & 309.8 & 12.5 \\
DLM & 1.2 & 0.01 & 2 & 89.7 & 7.19 & $>350$ & --- \\
\hline WTB & 0.8 & 0.01 & 2 & 59.0 & 7.57 & $>150$ & --- \\
WTB & 0.95 & 0.01 & 2 & 53.0 & 7.48 & $>150$ & --- \\
WTB & 1.1 & 0.01 & 2 & 58.2 & 7.59 & $>150$ & --- \\
\hline FEA & 0.6 & 0.0025 & 2 & 72.9 & 7.98 & $>250$ & --- \\
FEA & 0.8 & 0.0025 & 2 & 77.3 & 7.83 & $>250$ & --- \\
FEA & 0.9 & 0.0025 & 2 & 77.4 & 7.67 & $>250$ & --- \\
FEA & 0.95 & 0.0025 & 1 & 75.2 & 7.52 & 221.7 & 12.1 \\
FEA & 1.1 & 0.0025 & 2 & 98.7 & 7.80 & $>250$ & --- \\
FEA & 1.2 & 0.0025 & 2 & 119.5 & 7.91 & $>250$ & --- \\
\hline ZAERO & 0.8 & 0.0154 & 2 & 84.7 & 7.38 & $>257$ & --- \\
\hline ZEUS & 0.8 & 0.0154 & 2 & 89.0 & 7.42 & $>257$ & --- \\
ZEUS & 0.95 & 0.0154 & 1 & 74.9 & 7.16 & 226.3 & 12.2 \\
ZEUS & 1.1 & 0.0154 & 2 & 124.1 & 7.54 & $>448$ & --- \\
\hline
\end{tabular}
flutter mode was neutrally stable. The resulting dynamic pressure was considered to be the estimated $\mathrm{Q}_{\mathrm{f}}$, and the frequency of the neutrally stable mode was the estimate for $\mathrm{F}_{\mathrm{f}}$. That technique can also be used to generate interpolated models for arbitrary dynamic pressures, which was useful for comparing frequency responses for different models types at the same percentage of their respective flutter dynamic pressures. Normalizing based upon $\mathrm{Q}_{\mathrm{f}}$ served to considerably reduce the scatter in the frequency response comparisons. The DLM and WTB models had been residualized such that the internal structure of the models was not consistent from one dynamic pressure to the next so that it was not feasible to interpolate between the models. For the DLM and WTB models, the dynamic pressure interval was found that contained the flutter dynamic pressure. The unstable mode for the higher dynamic pressure case was identified and its frequency and damping were noted. The corresponding mode for the subcritical dynamic pressure was also identified along with its frequency and damping. Values for $\mathrm{Q}_{\mathrm{f}}$ and $\mathrm{F}_{\mathrm{f}}$ were then estimated using linear interpolation based upon the relative damping of the flutter mode for the subcritical and

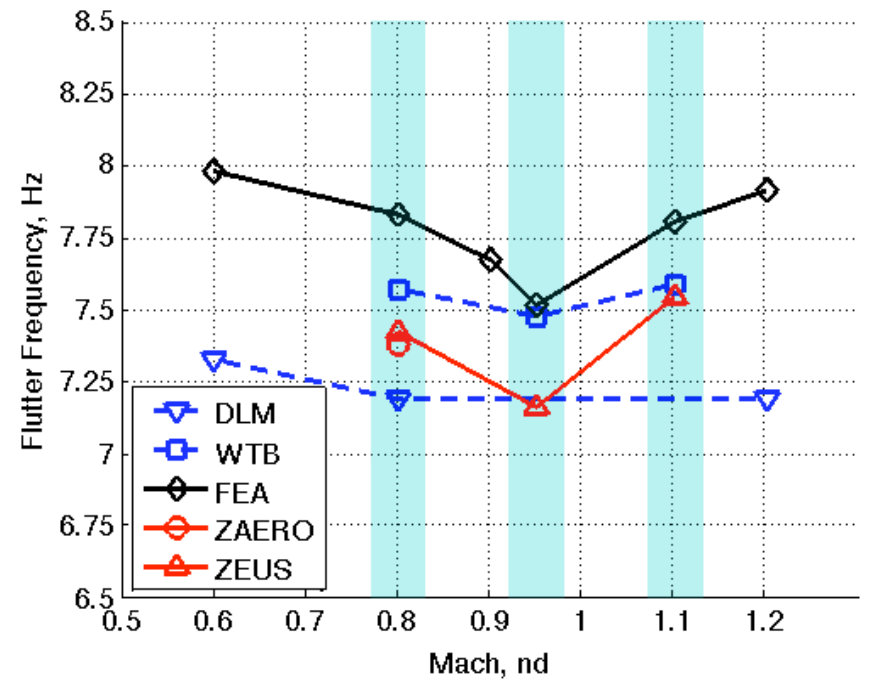

Figure 4. Analytical Flutter Frequency for $\mathbf{S}^{4} \mathrm{~T}$. Flutter frequency as function of Mach number and model source. postcritical conditions. The resulting interpolated value will be slightly different depending upon whether the interpolation parameter is dynamic pressure $\overline{\mathrm{q}}$ or velocity $(V)$ due to the nonlinear (quadratic) relationship between the two $\left(\overline{\mathrm{q}} \equiv \frac{1}{2} \rho V^{2}\right)$. The interpolation based upon the state-space matrices can be considered to introduce yet a third estimate for $\mathrm{Q}_{\mathrm{f}}$ and $\mathrm{F}_{\mathrm{f}}$, but since it is iterative it is at least insensitive to the choice of $\overline{\mathrm{q}}$ or $V$ as the interpolation parameter. The finer the dynamic pressure grid is to start with, the less the interpolation method will influence the estimates.

The change in flutter frequency as a function of Mach number is shown in Fig. 4 for the various analytical plant models. The curves show that the frequency at which flutter occurs stays within a range from 7 to $8 \mathrm{~Hz}$. Within that range the models show that the flutter frequency is lowest at Mach number 0.95 , and then increases for Mach numbers 1.1 and

American Institute of Aeronautics and Astronautics 
above. At Mach number 0.95 the change in slope for the curves is rather abrupt. If the lowering of the flutter frequency is associated with a transonic dip in the flutter dynamic pressure, it is possible that the "bottom" of that dip occurs between Mach numbers 0.95 and 1.1, which is plausible since the slender body and thin wing character of the $\mathrm{S}^{4} \mathrm{~T}$ tend to delay onset of transonic flow. ${ }^{14}$

\section{B. Analytical Plant Models - Frequency Responses}

Root locus eigenvalues are intrinsic to each analytical linear state-space model, independent of choice of sensor or control surface. However for feedback control, proper selection of control and sensor are important in terms of controllability, observability, and phasing. Certain sensors will respond more to one mode than to another, so a sensor that will observe the flutter mode while ignoring other modes would be a good choice for flutter suppression. Likewise, a control surface that is located at the pilot station would be expected to be in a good position to improve ride-quality for the pilot. That is in fact the reason why the RCV control surface was added to the TCA design. These kinds of differences are evident when comparing frequency responses for different sensor/control-surface pairs.
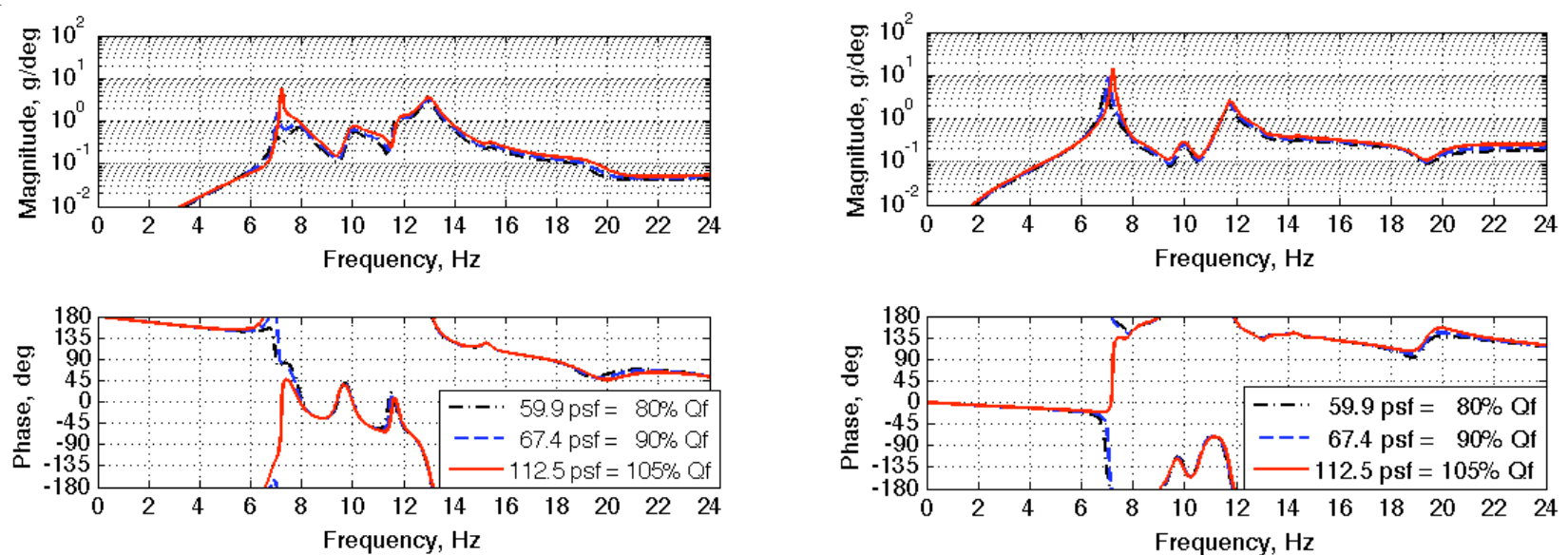

Figure 5. NIBAFTZ Sensor Response Due To HT Excitation. ZEUS analytical model for $\mathrm{M}=0.95$ for $S^{4} T$.

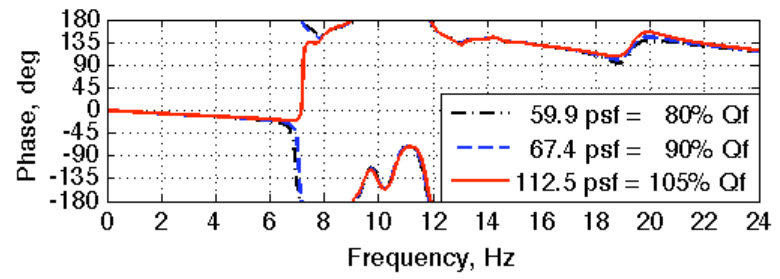

Figure 6. IBMID15I Sensor Response Due To FLAP Excitation. ZEUS analytical model for $\mathrm{M}=0.95$ for $S^{4} T$.

Frequency responses are shown for $\mathrm{M}=0.95$ for the nacelle inboard aft vertical accelerometer (NIBAFTZ, Fig. 2) due to excitation from the HT, and for the inboard middle vertical accelerometer number 15 (IBMID15I, Fig. 2) due to FLAP excitation, in Figs. 5 and 6, respectively. These were the two sensor/control-surface pairs that were used for the majority of the control laws that were tested. The frequency responses shown are for the ZEUS plant model for three dynamic pressures.

For the NIBAFTZ/HT curve at $80 \% \mathrm{Q}_{\mathrm{f}}$ in Fig. 5, there is a sharp $0.6 \mathrm{~g} / \mathrm{deg}$ peak in magnitude for the flutter mode at around $7 \mathrm{~Hz}$, and a broader $0.7 \mathrm{~g} / \mathrm{deg}$ peak at around $8 \mathrm{~Hz}$ for the companion mode that becomes more stable as the flutter mode becomes less stable at higher dynamic pressures. Other peaks are $0.5 \mathrm{~g} / \mathrm{deg} \mathrm{at} 10 \mathrm{~Hz}$, $1 \mathrm{~g} / \mathrm{deg}$ at $12 \mathrm{~Hz}$, and $3 \mathrm{~g} / \mathrm{deg}$ at $13 \mathrm{~Hz}$. At $90 \% \mathrm{Q}_{\mathrm{f}}$, the peak for the flutter mode has grown to about $1.5 \mathrm{~g} / \mathrm{deg}$, and the frequency has moved toward the frequency for the companion mode. At $105 \% \mathrm{Q}_{\mathrm{f}}$, the flutter mode peak is about $6 \mathrm{~g} / \mathrm{deg}$, and the phase plot confirms that the curve is for a condition above the open-loop flutter dynamic pressure because the frequency response leads $210 \mathrm{deg}$ rather than lagging 150 deg between 6 and $8 \mathrm{~Hz}$ as the two curves at lower $\overline{\mathrm{q}} \mathrm{do}$, for a net relative lead of $360 \mathrm{deg}$. That would correspond to a counter-clockwise circle on a Nyquist plot. One strategy for adding damping to the flutter mode would be to use a bandpass filter around $7.5 \mathrm{~Hz}$, with proper filtering to cause the peak to occur at 0 deg phase for the subcritical dynamic pressures, and at 180 deg phase for the case above the flutter dynamic pressure (assuming that the feedback signal is negated when closing the loop). The bandpass character would tend to avoid destabilizing the modes at $10 \mathrm{~Hz}$ and above, and also reduce the control law response to turbulence at frequencies below $7 \mathrm{~Hz}$. The phasing is crucial so that the signal is out of phase with itself when it completes a full feedback circuit (open-loop). Otherwise the feedback can act as an amplifier rather than an attenuator and actually cause premature instability.

The IBMID15I/FLAP curves in Fig. 6 illustrate the differences relative to the NIBAFTZ/HT curves in Fig. 5. The curve for $80 \% \mathrm{Q}_{\mathrm{f}}$ shows the flutter mode is excited at around $5 \mathrm{~g} / \mathrm{deg}$ (vs. $0.6 \mathrm{~g} / \mathrm{deg}$ ), but the $8 \mathrm{~Hz}$ companion mode and the $13 \mathrm{~Hz}$ mode are not even apparent. The peak near $12 \mathrm{~Hz}$ is about $2 \mathrm{~g} / \mathrm{deg}$ (vs. $1 \mathrm{~g} / \mathrm{deg}$ ), and the $10 \mathrm{~Hz}$

6

American Institute of Aeronautics and Astronautics 
mode is reduced to $0.25 \mathrm{~g} / \mathrm{deg}$ as compared to $0.5 \mathrm{~g} / \mathrm{deg}$ for the other sensor/control surface pair. Again, the curve at $90 \% \mathrm{Q}_{\mathrm{f}}$ shows growth in the amplitude of response for the flutter mode, and the $105 \% \mathrm{Q}_{\mathrm{f}}$ curve indicates the 360 deg jump in lead for the unstable flutter mode. A Single-Input, Single-Output (SISO) FS control law based upon this sensor/control pair would not need as much high frequency attenuation to achieve the same isolation of control effort relative to the higher frequency modes, because the response for those modes (at 10 and $13 \mathrm{~Hz}$ ) is already less while the response of the flutter mode itself is greater.

\section{Actuators}

One limitation related to using the FLAP as compared to the HT or RCV control surfaces is the limited range of travel. The physical range of travel for the FLAP is around $\pm 2.7 \mathrm{deg}$. with a software restriction limiting the range to \pm 2.5 deg. The limited FLAP range is related to the thinness of the wing, the limited space available for the actuator mechanism, and the aeroelastic mass and stiffness scaling targets. A full-scale vehicle would likely have a greater range of travel for the FLAP. The limited range of travel meant that the control surface could be at risk of hitting the stops and losing effectiveness in the presence of feedback response to turbulence. In comparison, the HT and RCV had physical range of travel of around $\pm 12 \mathrm{deg}$, with software restricting the range to $\pm 5 \mathrm{deg}$.

Concerning possible rate limits for the actuators, bench testing for the HT control surface indicated that at $7 \mathrm{~Hz}$ the amplitude of the model response even to the inertial (versus aerodynamic) loads would become unacceptably large before the characteristic saw-tooth waveform was reached for a rate-limited response to sinusoidal input. For a specified frequency, commanded rates are proportional to commanded deflections, so for the FLAP actuator, the position limits were the limiting factor rather than the commanded control rate. The RCV was not available at the time that the bench test was conducted, but it was designed to be driven with an actuator similar to the one for the HT, and the control

Table 2. Characteristics of Analytical Models, As Received.

\begin{tabular}{|c|c|c|c|c|c|c|c|c|}
\hline Model & $\begin{array}{c}\text { Mach } \\
\text { Number }\end{array}$ & $\overline{\mathrm{q}}_{\min }$ & $\overline{\mathrm{q}}_{\max }$ & $\begin{array}{c}\text { \# of } \\
\overline{\mathrm{q}} \text { 's }\end{array}$ & $\begin{array}{c}\text { \# of } \\
\text { States }\end{array}$ & $\begin{array}{c}\text { \# of } \\
\text { Sensors }\end{array}$ & $\begin{array}{c}\text { Controls } \\
(\mathrm{x} 3)\end{array}$ & $\begin{array}{c}\text { Turb. } \\
\text { Input }\end{array}$ \\
\hline DLM & 0.6 & 0 & 350 & 36 & $64-65$ & 8 & $\delta_{c}$ & -- \\
DLM & 0.8 & 0 & 350 & 36 & 64 & 8 & $\delta_{c}$ & -- \\
DLM & 1.2 & 0 & 350 & 36 & 64 & 8 & $\delta_{c}$ & -- \\
\hline WTB & 0.8 & 0 & 150 & 16 & $70-74$ & 10 & $\delta_{c}$ & $\sigma$ \\
WTB & 0.95 & 0 & 150 & 16 & $71-74$ & 10 & $\delta_{c}$ & $\sigma$ \\
WTB & 1.1 & 0 & 150 & 16 & $70-74$ & 10 & $\delta_{c}$ & $\sigma$ \\
\hline FEA & 0.6 & 0 & 250 & 51 & 180 & $51^{*}$ & $\delta, \dot{\delta}, \ddot{\delta}$ & $w_{g}, \dot{w}_{g}$ \\
FEA & 0.8 & 0 & 250 & 51 & 180 & 51 & $\delta, \dot{\delta}, \ddot{\delta}$ & $w_{g}, \dot{w}_{g}$ \\
FEA & 0.9 & 0 & 250 & 51 & 180 & 51 & $\delta, \dot{\delta}, \ddot{\delta}$ & $w_{g}, \dot{w}_{g}$ \\
FEA & 0.95 & 0 & 250 & 51 & 180 & 51 & $\delta, \dot{\delta}, \ddot{\delta}$ & $w_{g}, \dot{w}_{g}$ \\
FEA & 1.1 & 0 & 250 & 51 & 180 & 51 & $\delta, \dot{\delta}, \ddot{\delta}$ & $w_{g}, \dot{w}_{g}$ \\
FEA & 1.2 & 0 & 250 & 51 & 180 & 51 & $\delta, \dot{\delta}, \ddot{\delta}$ & $w_{g}, \dot{w}_{g}$ \\
\hline ZAERO & 0.8 & 20 & 257 & 25 & 73 & 38 & $\delta, \dot{\delta}, \ddot{\delta}$ & $w_{g}$ \\
\hline ZEUS & 0.8 & 20 & 257 & 25 & 73 & 38 & $\delta, \dot{\delta}, \ddot{\delta}$ & $w_{g}$ \\
ZEUS & 0.95 & 28 & 334 & 23 & 71 & 38 & $\delta, \dot{\delta}, \ddot{\delta}$ & $w_{g}$ \\
ZEUS & 1.1 & 37 & 448 & 23 & 71 & 38 & $\delta, \dot{\delta}, \ddot{\delta}$ & $w_{g}$ \\
\hline
\end{tabular}

* Includes 38 accelerometers and 13 loads outputs.

surface itself has a smaller moment-of-inertia and smaller surface area, so it is considered to be less likely to be subject to a rate limit than the HT. For the frequency range of interest, the vehicle response or the range of travel for the control surfaces were the active limits rather than any observable rate limit.

The FLAP and HT actuator dynamics were modeled in 2012 based upon fitting frequency responses derived from experimental data. The $2012 \mathrm{RCV}$ was modeled as being identical to the FLAP, although the actual actuator

Table 3. Properties of Actuator Models

\begin{tabular}{c|ccc|ccc}
\hline & \multicolumn{3}{|c|}{$\begin{array}{c}\text { Actuator Magnitude, } \\
\text { deg/deg @7 Hz }\end{array}$} & \multicolumn{3}{c}{ Actuator Phase, deg } \\
& RCV 7 Hz & \\
\hline Version & FLAP & HT & RCV & FLAP & HT \\
\hline 2012 & 1.00 & 1.00 & 0.92 & -20 & -20 & -37 \\
2010 & 0.96 & 0.96 & 0.96 & -44 & -38 & -41 \\
2008 & 0.96 & 0.96 & 0.42 & -29 & -23 & -218
\end{tabular}
installed for the RCV for the third and fourth wind tunnel tests had insufficient bandwidth even for plant identification, let alone for feedback control. All the actuator models are $3^{\text {rd }}$ order, primarily so that actuators have no direct feedthrough terms from command to control surface acceleration, even though $1^{\text {st }}$ or $2^{\text {nd }}$ order fits 
would likely provide adequate magnitude and phase characteristics, with possible time delay adjustments for lag. The FEA, ZAERO and ZEUS plant models accept position, rate and acceleration signals as inputs from the actuator models, as shown in Table 2. The DLM and WTB models incorporated actuator models internally, and were residualized such that it was not feasible to remove the existing actuator models and replace them with updated models. In the case of the HT, the original actuator hardware was severely bandwidth limited and it was replaced prior to the $3^{\text {rd }}$ wind-tunnel test with a much better actuator previously installed on the RCV. Unfortunately, the WTB model still uses a model for the HT response based upon the older, unsuitable actuator. Magnitude and phase characteristics at $7 \mathrm{~Hz}$ for the various actuator models are shown in Table 3. Actuator models impact frequency responses associated with a particular control surface, but have no impact on eigenvalues associated with the root locus shown in Fig. 3 or the model flutter dynamic pressure or frequency shown in Table 1. All analytical plant frequency responses shown in this paper incorporate the 2012-actuator models, where feasible, or the internal actuators for the DLM and WTB plant models.

\section{Control Objectives and Constraints}

One of the main goals of the third wind tunnel entry was to test control laws for RQE, GLA, and FS functionality and to assess their performance. One limitation was that all testing was to be conducted below the open-loop flutter dynamic pressure. The fourth tunnel entry provided an opportunity to be more aggressive in probing the flutter boundary while operating open-loop, and to test control laws closed-loop while operating above the open-loop flutter dynamic pressure. Control law development techniques, and test results for the third tunnel entry are published in references 12 and 13. Control law characteristics, and RQE and GLA performance metrics from the third test will be only briefly summarized in this paper. With regard to FS performance, results from the fourth tunnel entry supersede those from the third, and will be presented in more depth.

Metrics were developed for each of the RQE, GLA, and FS functions, along with a goal with respect to each metric. Both the RQE and GLA metrics used a similar technique, but were based upon different sensors. The technique was to take open-loop and closed-loop data at ambient tunnel conditions, calculate Power Spectral Density (PSD) curves for the response to tunnel turbulence as functions of frequency, and compare the results. Unlike frequency responses,

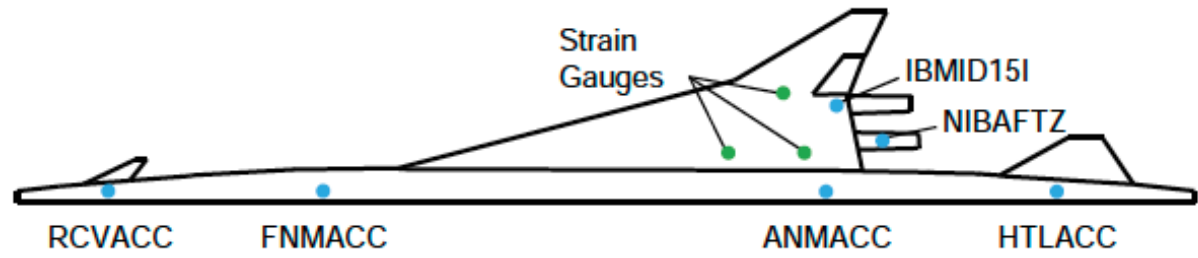

Figure 7. Sensors used for RQE and GLA metrics and for feedback. PSD's only require output measurements so they were available without measuring the turbulence. The metric was the square root of the integral of the PSD's over a frequency range from 0 to $30 \mathrm{~Hz}$, effectively giving a low-passed Root Mean Squared (RMS) value by means of evaluation in the frequency domain.

The sensors used for the RQE metric were the four vertical accelerometers located along the flexible fuselage beam. They were the RCV accelerometer (RCVACC), forward nodal mount accelerometer (FNMACC), aft nodal mount accelerometer (ANMACC) and the horizontal tail accelerometer (HTLACC) (see Fig. 7). The metric was tracked for each accelerometer separately. A reduction in the value of this metric would indicate a smoother ride for the passengers, or possibly improve the flying qualities for the pilot in the case of the RCVACC accelerometer. The goal was a $20 \%$ reduction in the metric value closed-loop as compared to open-loop at the same tunnel condition.

The sensors used for the GLA metric were strain gauges located on the wing. Two of the locations were at the wing root and one was at about midspan, aft of the crank in the leading edge of the wing. The strain gauges were calibrated using static loading for bending, torsion, and shear. The GLA metric was based on three linear combinations of these strain sensors, mapped to units of forces or moments as loads. Reduction in the value of this metric would indicate reduced fatigue load on the wing, and possibly an extended fatigue life for the airframe. The goal was a $20 \%$ reduction in the metric value, closed-loop as compared to open-loop.

For the FS metric, the desire was to show an increase in the dynamic pressure for flutter, closed-loop as compared to open-loop. The metric was estimated from subcritical test conditions for the third wind tunnel test, and from sub- and postcritical conditions for the fourth wind tunnel test. Flutter probes would be discontinued if model response to turbulence became too large, or if near-real-time processing of time history data using Controller Performance Evaluation (CPE) ${ }^{15}$ software indicated that gain or phase stability margins, or more generally, minimum singular values, were getting unacceptably small. Minimum singular values for the return difference 
matrices at the sensors and at the controls, open-loop, were required to be 0.3 or greater in order to close the feedback control loop. When operating near the open-loop flutter boundary, the control loop would be closed, and then remain closed while progressing to a higher dynamic pressure test condition. When reassessing at a higher $\overline{\mathrm{q}}$, singular values less than 0.3 would be grounds for discontinuing a flutter probe. A stated goal was an increase in the flutter speed of $20 \%$, which corresponds to an increase in flutter dynamic pressure of $44 \%$. It was not the intention to demonstrate actual flutter onset either open- or closed-loop, so any projections of the dynamic pressure for closed-loop flutter are based upon extrapolation of some sort. For the open-loop boundary, CPE analysis was used to establish upper and lower bounds on open-loop flutter from closed-loop testing.

\section{Control Law Characteristics}

Eleven control laws were tested closed-loop during the third and fourth wind tunnel tests of the $\mathrm{S}^{4} \mathrm{~T}$. Five were tested only during the third tunnel entry, five were tested in both the third and fourth tunnel entry, and one was introduced for testing during the fourth tunnel entry (see Table 4). The eleven control laws that were tested were a subset of a much larger set, but they represent the control laws that were deemed to be most likely to succeed. Rather than using the names ascribed to them in previous publications which require context for design Mach number and designer team, the names shown in Table 4 are unique identifies associated with the data files defining the control laws. Identification with names from previous publications can be made by the control law descriptions.

\section{A. Control Law Designs}

M4 Engineering developed and tested a flutter suppression control law for each of the three target Mach numbers, and a gust load alleviation control law for the transonic $\mathrm{M}=0.95$ test condition. The order of the control laws was 18, 18, and 19 for FS, and 21 for GLA. The method used was initially full state feedback Linear Quadratic Regulator (LQR) design, which was then modified with a Kalman Filter state estimator using a Linear Quadratic Gaussian (LQG) method. The Loop Transfer Recovery (LTR) technique was used to achieve increased robustness. ${ }^{12}$ The control laws were designed using reduced order models, and were evaluated using full order models. The design point for the FS control laws was at a dynamic pressure above the open-loop $\mathrm{Q}_{\mathrm{f}}$, and it was found that for the analytical models, scheduling control law parameters as functions of dynamic pressure would be useful for extending the range of penetration beyond the open-loop flutter boundary. The GLA control law was multiinput/multi-

output (MIMO), using two control surfaces and two sensors. Each FS control law was SISO, using one control surface and one sensor. The FS control laws were tested during both the third and the fourth wind tunnel entries, but the GLA control law was only tested during the third wind tunnel entry.

Table 4. Control Laws Tested.

\begin{tabular}{|c|c|c|c|c|c|c|c|c|c|}
\hline Team & Name & $\begin{array}{l}\text { Mach } \\
\text { No. }\end{array}$ & Type & Method & Order & Sensor & Control & $\begin{array}{l}\text { 3rd } \\
\text { Test }\end{array}$ & $\begin{array}{l}\text { 4th } \\
\text { Test }\end{array}$ \\
\hline M4 & CL121 & 0.80 & $F$ & LQG/LTR & 18 & NIBAFTZ & $\mathrm{HT}$ & Yes & Yes \\
\hline ZONA & v16 & 0.80 & $\mathrm{R} / \mathrm{F}$ & Robust & 19 & NIBAFTZ & $\mathrm{HT}$ & Yes & Yes \\
\hline ZONA & v437 & 0.80 & $\mathrm{~F} / \mathrm{R} / \mathrm{G}$ & Classic & 4 & $\begin{array}{l}\text { IBMID15I } \\
\text { HTLACC }\end{array}$ & $\begin{array}{l}\text { FLAP } \\
\text { HT }\end{array}$ & Yes & No \\
\hline M4 & 221 & 0.95 & $\mathrm{~F}$ & LQ & 18 & NIBAFTZ & HT & Yes & Yes \\
\hline M4 & CL227 & 0.95 & G & LQG/LTR & 21 & $\begin{array}{l}\text { NIBAFTZ } \\
\text { NOBAFTZ }\end{array}$ & $\begin{array}{l}\text { FLAP } \\
\text { HT }\end{array}$ & Yes & No \\
\hline ZONA & v25 & 0.95 & $\mathrm{~F}$ & Robust & 15 & NIBAFTZ & $\mathrm{HT}$ & Yes & No \\
\hline ZONA & v448 & 0.95 & $\mathrm{R} / \mathrm{G}$ & Clas & 6 & $\begin{array}{l}\text { IBMID15I } \\
\text { NIBAFTZ }\end{array}$ & $\begin{array}{c}\text { FLAP } \\
\text { HT }\end{array}$ & Yes & Yes \\
\hline M4 & CL321 & 1.10 & $F$ & LQG/LTR & 19 & NIBAFTZ & HT & Yes & Yes \\
\hline ZONA & v20 & 1.10 & $\mathrm{~F}$ & Robust & 9 & NIBAFTZ & $\mathrm{HT}$ & Yes & No \\
\hline ZONA & v549 & 1.10 & $\mathrm{R} / \mathrm{G}$ & C & 6 & $\begin{array}{l}\text { IBMID15I } \\
\text { NIBAFTZ }\end{array}$ & $\begin{array}{l}\text { FLAP } \\
\text { HT }\end{array}$ & Yes & No \\
\hline LM & s884 & 1.10 & $\mathrm{~F}$ & Nyquist & 11 & NIBAFTZ & HT & No & Yes \\
\hline
\end{tabular}

Zona Technology used two general methods for designing control laws, Classic and Robust. ${ }^{13}$ The term Robust refers to either $\mathrm{H}$-infinity or $\mu$-synthesis design, and the techniques produce compensators that provide guaranteed stability for the closed-loop system, provided that the deviations from the design case are bounded by the level of uncertainty assumed during the design process. The Classic approach can refer to such things as Evans (gain) Root Locus, Bode, Nyquist, or Nichols design techniques for linear systems. In this case, the Robust design resulted in a SISO FS control law for each Mach number, with compensator order 19, 15, and 9 for Mach numbers 0.8, 0.95, and 
1.1, respectively. The Classic approach resulted in a MIMO (two-control-surface/two sensor) control law of order 4, 6 , and 6 for each of the three Mach numbers, primarily for RQE and GLA functionality but also with a modest FS capability for the $\mathrm{M}=0.8$ case. Each Classic MIMO control law is actually two SISO control laws working in parallel with each other with no cross-talk within the control law. All six control laws were tested during the third wind tunnel entry, but only the v16 SISO Robust controller for $\mathrm{M}=0.8$ and the $\mathrm{v} 448$ MIMO Classic controller for $\mathrm{M}=0.95$ were tested during the fourth wind tunnel entry. The v16 controller was considered to be primarily effective for $\mathrm{RQE}$, and only secondarily for FS. The v448 controller was not even rated for FS, showing the degree of overlap between the various control law functions, for these designs with this plant.

The Lockheed FS control law for Mach number 1.1 was based strictly on classical SISO Nyquist loop-shaping techniques, using experimentally derived estimates of the plant frequency response for a subcritical dynamic pressure as generated by the CPE software. A washout filter was used below the flutter frequency in order to be insensitive to steady state sensor bias and to reduce control law response to turbulence. Attenuation was also used above the flutter frequency to avoid interaction with higher frequency structural modes. The primary feedback gain was in the flutter frequency range between 5 and $10 \mathrm{~Hz}$, and the various filters were adjusted such that the phasing of the plant in series with the control law (loop transfer function) at the flutter frequency would be 0 deg subcritically (for negative feedback when closing the feedback loop). The intention was that when probing beyond the open-loop flutter boundary, the Nyquist loop will reverse polarity and encircle the critical point located at magnitude 1 and phase $\pm 180 \mathrm{deg}$. The Lockheed control law was a design of opportunity rather than a contractural requirement, and it was included in the test plan for the fourth wind-tunnel entry only after all major objectives of the test program had been met.

\section{B. Control Law Dynamics - Fourth Wind-Tunnel Test}

Six FS control laws were tested during the fourth wind tunnel entry, two each for Mach numbers $0.8,0.95$ and 1.1. Frequency responses for M4's three LQG/LTR FS control laws can be seen as the blue curves in Figs. 8, 9, and 10a. It can be observed that these control laws are similar to each other across the Mach number range. An encouraging implication of that is that a single control law or a reasonably scheduled control law may be able to operate across a range of Mach numbers, even through the transonic regime. The LQG/LTR control laws have frequency response characteristics similar to those described in the design steps for the LM Nyquist design (Fig. 9), to include a low frequency wash-out, high frequency notches and attenuation, and appreciable signal strength in the vecinity of the flutter frequency.

The differences between the Zona Robust and Classic dynamics are very much apparent (Fig. 8 vs. Figs. 10a $\& 10 \mathrm{~b})$. The frequency response for the Robust design at Mach number 0.8 is similar in character to the LQG designs. However, the frequency responces for the two parallel channels of the Classic MIMO control law for Mach number 0.95 are quite differnt. The Classic frequency responses are clearly low order, and show no peak at all at the flutter frequency range around $7.5 \mathrm{~Hz}$. There is a minimalistic washout for both channels to avoid responding to steady-state bias, but primarily the frequency responses are very flat. The HT/NIBAFTZ channel (Fig. 10a) peaks at a gain of about $0.7 \mathrm{deg} / \mathrm{g}$ at around $0.5 \mathrm{~Hz}$, but has a gain of about $0.1 \mathrm{deg} / \mathrm{g}$ at $7.5 \mathrm{~Hz}$ and declines gradually for
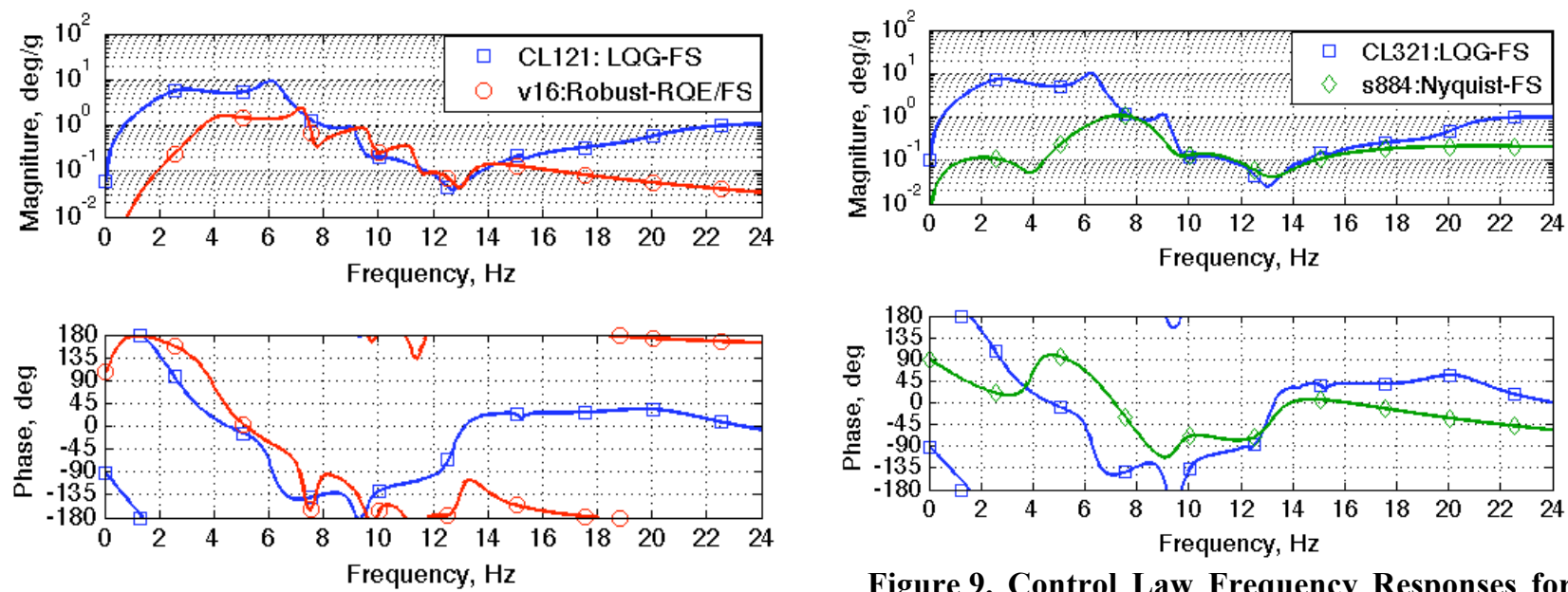

Figure 8. Control Law Frequency Responses for $\mathbf{M}=\mathbf{0 . 8}$ for Fourth Wind Tunnel Entry. HT command due to NIBAFTZ sensor.

Figure 9. Control Law Frequency Responses for M=1.1 for Fourth Wind Tunnel Entry. HT command due to NIBAFTZ sensor. 
higher frequencies. The phase is almost constant at -85 to -90 deg above $5 \mathrm{~Hz}$. For the FLAP/IBMID15I channel (Fig. 10b), the phase lags gradually from $-180 \mathrm{deg}$ at $4 \mathrm{~Hz}$ to $-235 \mathrm{deg}$ at $24 \mathrm{~Hz}$ while the magnitude declines from about $1 \mathrm{deg} / \mathrm{g}$ at $4 \mathrm{~Hz}$ to $0.5 \mathrm{deg} / \mathrm{g}$ at $24 \mathrm{~Hz}$. Since there is no magnitude peak to target the flutter mode, the phasing across a broad frequency band needs to be such that the flutter mode is damped rather than amplified. The phasing of the two channels of the Classic control law can be compared to the phasing of the corresponding channels for the plant model, as shown in Figs. 4 and 5. Because of the flat response with respect to frequency, this control design should be nearly insensitive to changes in the frequency of the flutter mode as it crosses into the unstable region in the right half plane.

The frequency response for the LM Nyquist control law looks more similar to the dynamics for the LQG/LTR or Robust control laws than it does to the dynamics for the Classical control law. It has a washout at low frequency, notches and attenuation at high frequencies, and a broad peak in the flutter frequency range. A notable difference between the Nyquist design and the LQG/LTR design for the M=1.1 case is that the Nyquist design has about 90 deg more lead than the LQG/LTR design. The difference is likely related to the subcritical dynamic pressure design case for the Nyquist design compared to the preferred post-critial design case for the LQG/LTR design. Another difference is that the LGQ/LTR control law has less attenuation below the frequency range of the flutter mode. That may result in undesirable control surface activity at lower frequencies in response to turbulence.
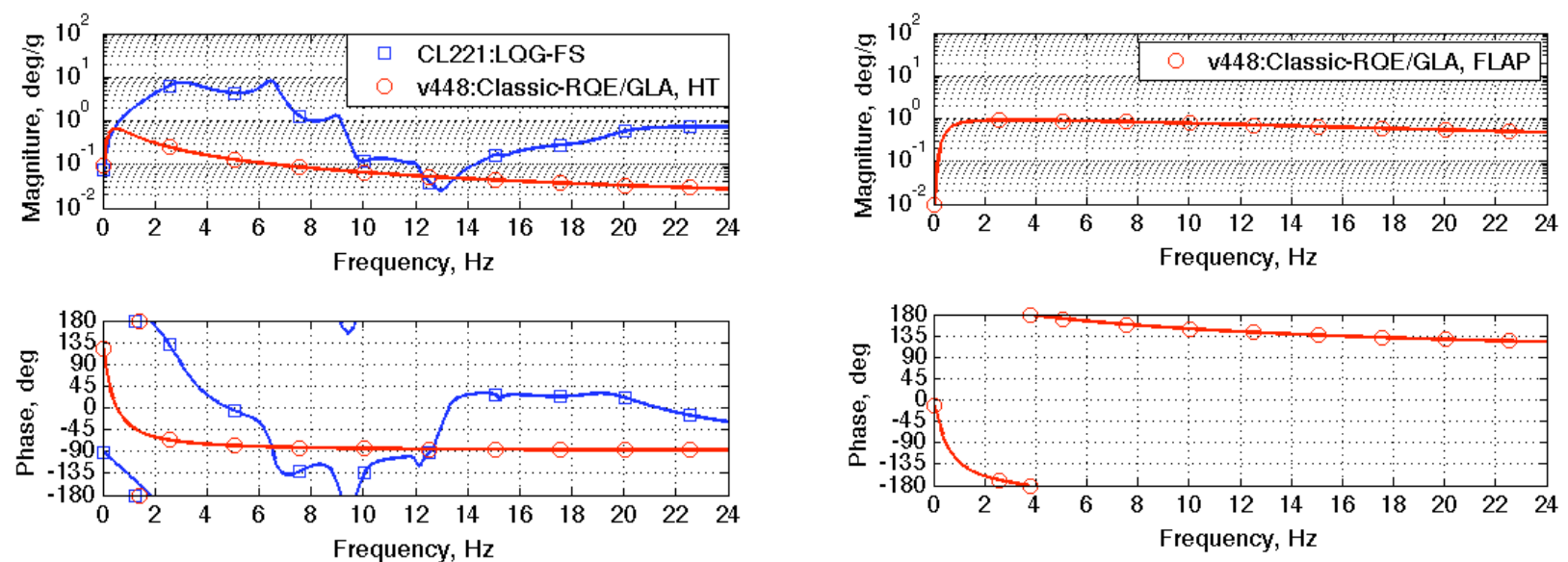

Figure 10a. Control Law Frequency Responses for M=0.95 for Fourth Wind Tunnel Entry. HT command due to NIBAFTZ sensor.

Figure 10b. Control Law Frequency Response for $\mathbf{M = 0 . 9 5}$ for Fourth Wind Tunnel Entry. FLAP command due to IBMID15I sensor.

\section{Padding and Discretization}

The control laws were implemented in discrete digital form in a dedicated computer in the wind-tunnel control room. Analog-to-digital and digital-to-analog conversions were applied to the sensor signals and to the contol law commands to the servo controller. The servo controller controlled the flow of hydraulic fluid to the actuators to cause the desired motion of the model control surfaces. The digital control computer ${ }^{3}$ had a standard interface to the control laws that was developed in Simulink ${ }^{*}$ and implementd through Real Time Workshop (RTW) ${ }^{*}$. The standard interface required a discrete state space model, padded to 40 state variables, 3 channels of control commands, and either 18 channels for sensor feedback signals for the third wind tunnel entry, or 7 sensor feedback signals for the fourth wind tunnel entry.

Actually, two such control laws could be loaded at once and the system then compiled into realtime software. The test director could then select between one control law or the other without recompiling. For the selected control law, the feedback signal to the controls could be disengaged or engaged, for open-loop or closed-loop operation. Excitation signals could also be added to the system either at the controls or at the sensors. Excitation and response signals from the controls and feedback sensor list could then be processed in near real time by the CPE software for frequency response estimation and for singular value and determinant plot analysis. Data for a full list of 38 accelerometers and 12 strain gauges, as well as for tunnel conditions, model angle-of-attack, and many other signals were recorded on the TDT Data Acquisition System (DAS), available for post processing for quantities such as the RQE and GLA metrics.

\footnotetext{
* Simulink, Real Time Workshop, and MATLAB are trademarks of MathWorks, Inc.
} 
The sample rate for the system was changed from 500 samples-per-second to 1000 samples-per-second during the second wind tunnel entry, and was maintained at 1000 samples-per-second throughout the third and fourth wind tunnel entries. With the Nyquist frequency originally $250 \mathrm{~Hz}$ and subsequently increased to $500 \mathrm{~Hz}$, the frequency compression due to discretization of the continuous control laws was negligeable at the $7.5 \mathrm{~Hz}$ frequency range of interest for flutter suppression. The procedure for the control law designers was that the control laws were to be delivered as continuous state-space models in MATLAB ${ }^{*}$ Linear Time Invariant (LTI) objects. NASA was then able to generate a discrete LTI object based upon the appropriate sample rate and perform the necessary state, input, and output variable padding. Because of the large frequency separation between the Nyquist frequency and the control frequency, no prewarping of the control law dynamics was required and a standard Tustin bilinear transformation was applied for the continuous-to-discrete conversion.

\section{Experimental Results}

Open-loop flutter onset was avoided during the fourth wind tunnel entry by testing closed-loop when approaching the open-loop flutter boundary, and by relying on CPE analysis to assist in determining whether the risk was acceptable to proceed to the next higher dynamic pressure, open- or closed-loop. None of the control laws were tested to closed-loop flutter onset. The open-loop flutter boundary was successfully penetrated for Mach numbers 0.8 and 0.95 , but the open-loop flutter boundary at $\mathrm{M}=0.95$ posed an operational constraint that limited testing at Mach number 1.1 to subcritical dynamic pressures. Examples are given for the CPE stability margin assessment process.

\section{A. CPE Stability Analysis}

On-site software analysis tools ${ }^{15}$ were instrumental in being able to evaluate the control laws. Figure 11 shows analysis for the Zona v448 Classic MIMO 2-by-2 control law, operating open-loop below the flutter boundary at Mach number 0.95 , dynamic pressure $70 \mathrm{lb} / \mathrm{ft}^{2}$. The top two plots show return-difference minimum singular values
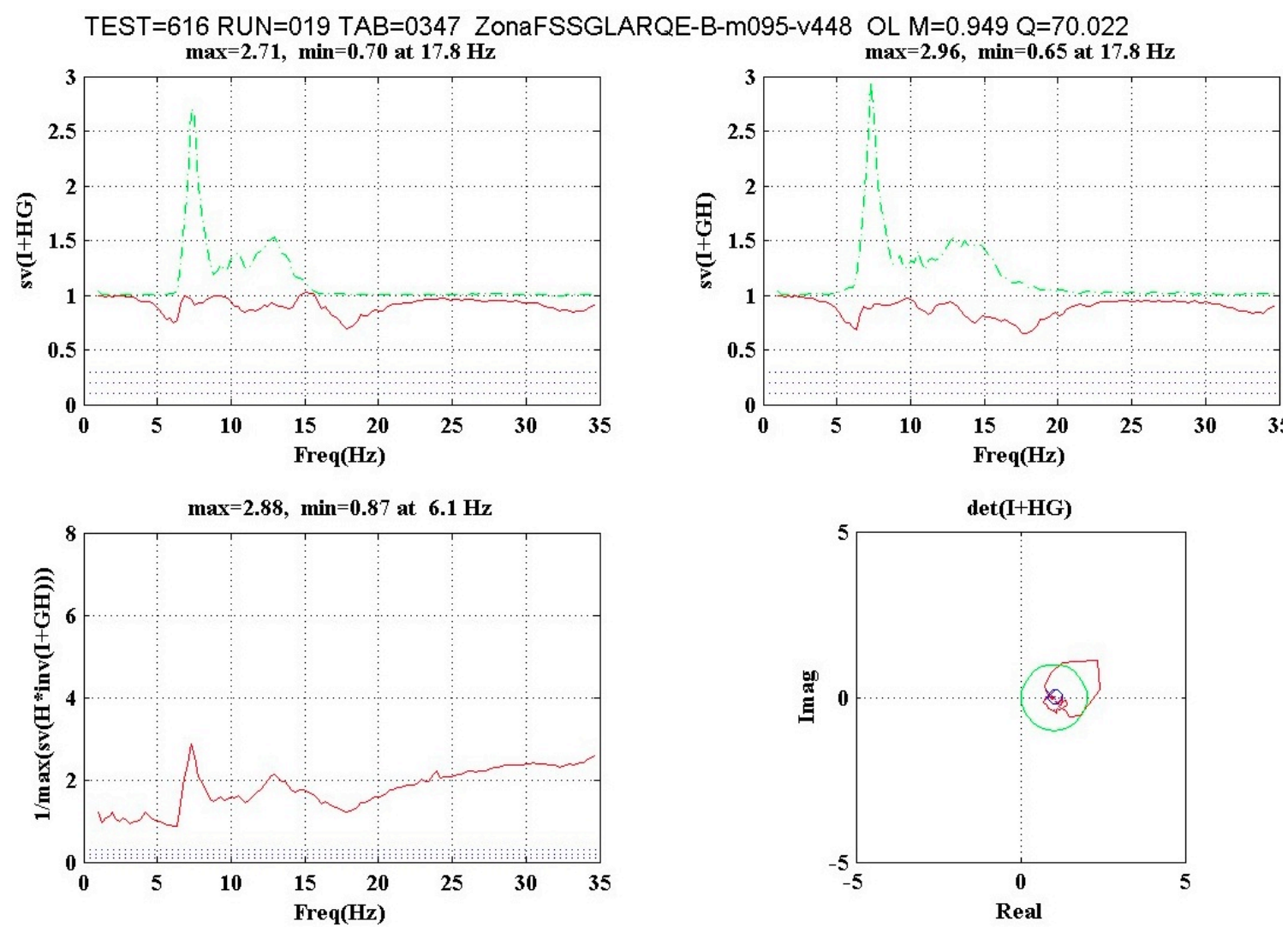

Figure 11. Quad-Plot for Open-Loop v448 Classic MIMO Control Law, M=0.95, Q=70 lb/ft ${ }^{2}$. Top left: singular values at control commands. Top right: singular values at feedback sensors. Bottom left: reciprocal of controller gain singular values. Bottom right: Generalized Nyquist Plot. 
(MSV's) defined at the controls (left) and at the sensors (right). In the axis labels, $\mathrm{G}$ and $\mathrm{H}$ refer to frequencydependent transfer function matrices for the plant and for the control law with units of $\mathrm{g} / \mathrm{deg}$ and $\mathrm{deg} / \mathrm{g}$, respectively. HG represents a loop transfer matrix for the plant in series with the control law, and has units of $\mathrm{deg} / \mathrm{deg}$. GH is another loop transfer function for the control law in series with the plant, and it has units $\mathrm{g} / \mathrm{g}$. Adding an appropriately sized identity matrix to either loop transfer matrix turns it into a return difference matrix, and the singular values of the return difference matrix give an indication of stability margins. Small singular values at some frequency indicate small stability margins at that frequency.

Since the v448 control law uses two control surfaces, the upper left plot shows two curves. The lower of the two curves gives an indication of stability margin for uncertainties as defined at the controls. The upper right plot has two curves because the control law uses two sensors for feedback, and the lower curve on that plot gives an indication of stability margin for uncertainties as defined at the sensors. The lower right plot shows the determinant of the return difference matrix as defined at the control commands. It is identical to a determinant plot for the return difference matrix defined at the sensors. Since steady-state control is not the current purpose, the determinant plot is shown for only positive frequencies (i.e. the mirror image plot for negative frequencies is suppressed). An encirclement of the critical point for the determinant plot is an indication of a change in stability if the feedback loop is closed for an open-loop system, or if the loop is opened for a closed-loop system.

The interpretation of the Fig. 11 plots is that closing the feedback loop would not destabilize the plant (no clockwise encirclement of the critical point when traversing the determinant plot curve from low to high frequency). The system would have adequate gain and phase margins, and acceptable minimum singular values in the vicinity of the flutter frequency. For the wind-tunnel test, the minimum allowable MSV was 0.3 on either of the top two plots. In fact, the lowest singular value occurs at $17.8 \mathrm{~Hz}$, well above the flutter frequency, and it has a satisfactory value of 0.70 for breaking the feedback loop at the controls, and 0.65 for breaking the loop at the sensors. This control law was tested closed-loop during a later test run (35 vs. 19) and was successfully able to suppress flutter at dynamic pressure $100.5 \mathrm{lb} / \mathrm{ft}^{2}$, about $9 \%$ above the open-loop flutter boundary.

Figure 12 shows results from testing closed-loop above the open-loop flutter boundary for the M4 CL121 SISO FS control law at Mach number 0.8 and dynamic pressure $90 \mathrm{lb} / \mathrm{ft}^{2}$. Note that for the SISO controller, there is only a single curve represented on the top two plots, and the curves are identical. That is because there is no difference between breaking the feedback loop at the commanded control deflections (left) or at the sensors (right) for the SISO case and there is only one channel involved in either case.

The plot at the lower left shows the reciprocal of only the maximum singular value associated with the controller gain at each frequency, so only a single curve is present even for MIMO control laws. Unlike the return difference MSV's which are nondimensional, the reciprocal of the controller gain MSV's have units of $\mathrm{g} / \mathrm{deg}$, and a different choice of units would result in different values for this metric. However, experience has shown that g's and deg's tend to be a fairly well balanced choice for units. For Fig. 12, the value $0.12 \mathrm{~g} / \mathrm{deg}$ at $5.6 \mathrm{~Hz}$ is small enough that high gain may be a concern, with the potential consequence of excessive control activity at low frequency or sensitivity to mischaracterization of the plant.

The plot in the lower right shows a generalized Nyquist curve for the SISO case, with the critical point shifted to the origin as is necessarily the case for the determinant plot of the return difference matrix for MIMO systems. For the SISO case, this shift can be considered to be looking at the return difference signal rather than at a return difference matrix, because it does not represent multiple signals. The time history data for this tunnel condition were collected closed-loop, but the generalized Nyquist curve represents the open-loop return difference derived from closed-loop data. The curve shows a counter-clockwise encirclement of the critical point, which is a clear indication that this system would be unstable if the feedback were turned off.

The return-difference MSV is 0.70 at $13.9 \mathrm{~Hz}$, well above the flutter frequency, indicating adequate stability margins. For this SISO case, the singular values are simply the distance in the complex plane between the return difference curve and the critical point. Small singular values indicate proximity to a change in the encirclement condition, which is an indication of a change in stability with change in loop closure status. Gain and phase margins can be determined graphically from the plot. Phase margins are determined as the angle between the critical point and the points where the return difference curve crosses the green unit circle. Lead sensitivity is determined by the low-frequency "North" crossing and lag sensitivity is determined by the high-frequency "South" crossing. Gain margins are determined by the magnitude where the return difference curve crosses the \pm 180 deg line. Raising the gain by a factor of 2.5 would destabilize this system at high frequency. Since this system relies upon feedback for stability, lowering the gain by a factor of about 2.5 would expose the instability at the flutter frequency itself.

If the determinant plot for the MIMO case is used to determine gain and phase margins, the interpretation can be dangerously misleading. MIMO determinant gain and phase margins indicate tolerance to uniform gain and phase

13

American Institute of Aeronautics and Astronautics 
changes across all channels. However, by their nature MIMO control systems are subject to various gain and phase differences on each of multiple channels, which is much more likely to contain the critical case rather than uniform gain and phase changes. The return difference singular values are a somewhat conservative measure of margins, in that they indicate a norm bound on the worst possible combination of changes on multiple channels. However, they are more realistic than the determinant gain and phase, and are in principle reliably conservative.

TEST=616 RUN=022 TAB=0462 M4FSS-C-m080q150-DLM-CL121 CL M=0.800 Q=90.140 $\max =2.63, \min =0.70$ at $13.9 \mathrm{~Hz}$
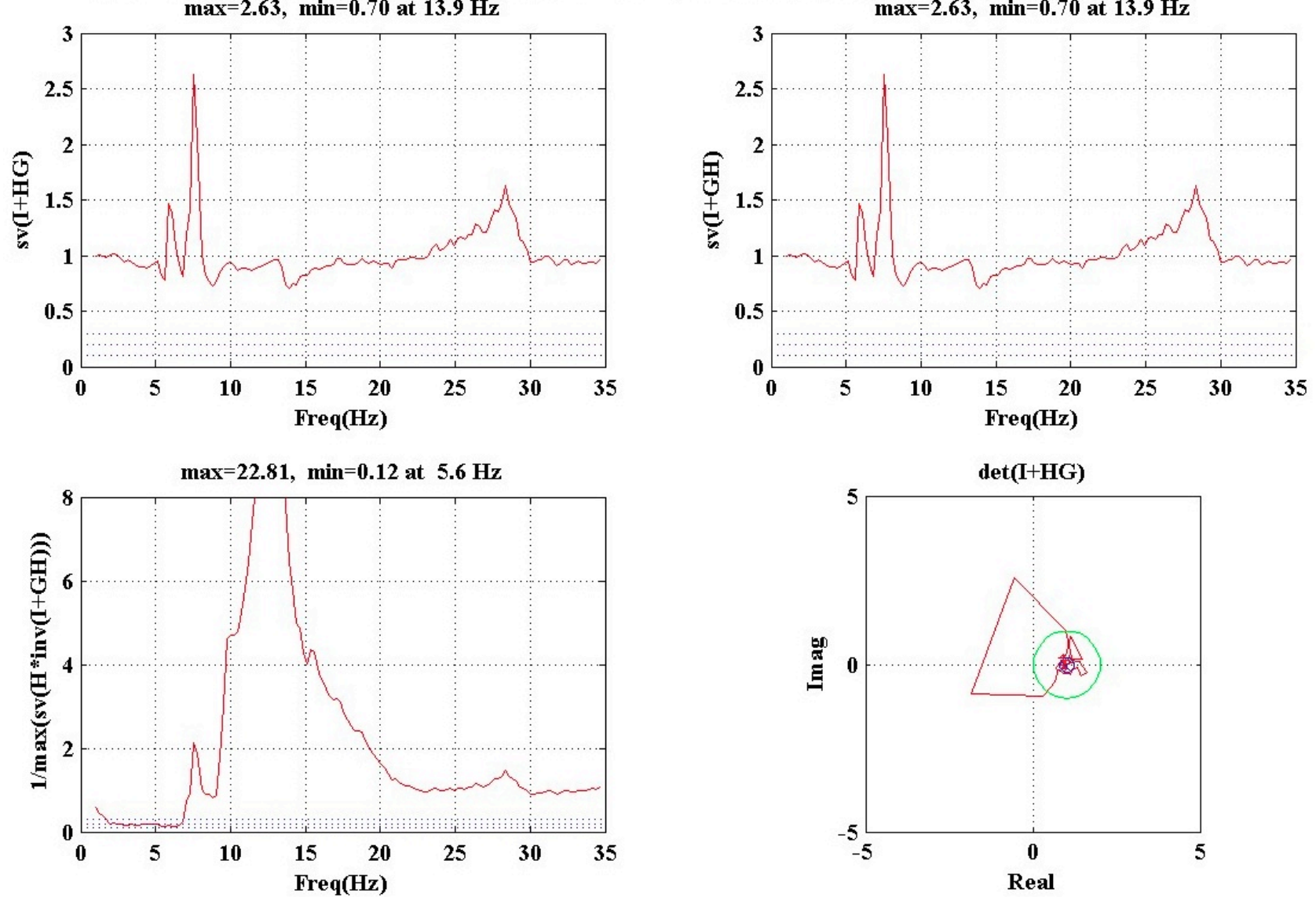

Figure 12. Quad-Plot for Closed-Loop CL121 LQG/LTR SISO Control Law, M=0.8, Q=90 lb/ft ${ }^{2}$. Top left: singular values at control commands. Top right: singular values at feedback sensors. Bottom left: reciprocal of controller gain singular values. Bottom right: Generalized Nyquist plot.

The return difference MSV's are a measure of distance from a stability boundary, but in themselves do not indicate whether change in loop closure status will change the stability of the system. The determinant plot is absolutely necessary for distinguishing whether closing the loop on an open-loop stable system will cause the system to become unstable. An open-loop system can have a (destabilizing) clockwise encirclement of the critical point, and still have acceptably large singular values. Likewise, the determinant plot is necessary for interpreting whether opening the loop for a closed-loop system will expose an open-loop unstable condition. A counterclockwise encirclement closed-loop indicates the open-loop system would be unstable.

\section{B. Highest Dynamic Pressure Tested, Closed-Loop}

The dynamic pressure for which the analytical models become unstable is shown in Fig. 13 as a function of Mach number. The Mach numbers for which test data are available are highlighted as the shaded columns. Also shown are experimental estimates for $\mathrm{Q}_{\mathrm{f}}$ for $\mathrm{M}=0.8$ and $\mathrm{M}=0.95$, which are plotted as $88 \mathrm{lb} / \mathrm{ft}^{2}$ and $92 \mathrm{lb} / \mathrm{ft}^{2}$, respectively. For Mach number 1.1, the flutter probe was restricted from going above nominally $\overline{\mathrm{q}}=100 \mathrm{lb} / \mathrm{ft}^{2}$ due to concerns that coming back down in tunnel speed would traverse the region of instability at Mach number 0.95 , so $101.1 \mathrm{lb} / \mathrm{ft}^{2}$ represents only a lower bound on $\mathrm{Q}_{\mathrm{f}}$ for that Mach number. For all cases where experimentally-based 
estimates are available, the analytical models proved to be either accurate or conservative in predicting the flutter boundary. A lowering of the flutter boundary in the transonic region as predicted analytically was not observed experimentally. However, it may still be present in the gap between Mach numbers 0.95 and 1.1 where no data were collected. The increase in dynamic pressure for flutter for the supersonic case was generally confirmed, by means of the lower bound. The highest dynamic pressures for which control laws were tested closed-loop are shown in Table 5. Both the CL321 LQG/LTR and the s884 Nyquist control laws were tested to the supersonic operational limit for the $\mathrm{S}^{4} \mathrm{~T}$, which was open-loop stable, so neither was able to directly demonstrate actual flutter suppression. The s884 control law was starting to show a low frequency lead sensitivity at the higher $\overline{\mathrm{q}}$ 's, which would indicate that a higher design $\overline{\mathrm{q}}$ would be recommended. The return difference MSV for the CL221 LQG/LTR control law at $\mathrm{M}=0.95$ was 0.63 at $\overline{\mathrm{q}}=80 \mathrm{lb} / \mathrm{ft}^{2}$, which would be considered acceptable for going to higher $\overline{\mathrm{q}}$. However, the reciprocal of the controller gain MSV for the same condition was $0.08 \mathrm{~g} / \mathrm{deg}$ at low frequency. The small value indicates high gain and possible excessive control activity and vehicle response in the presence of turbulence. Similar MSV values can be seen in Fig. 12 for a $M=0.8$ condition. For Mach number 0.8 , both the CL121 LQG/LTR and the v16 Robust control laws were able to demonstrate closed-loop operation above the open-loop flutter boundary.

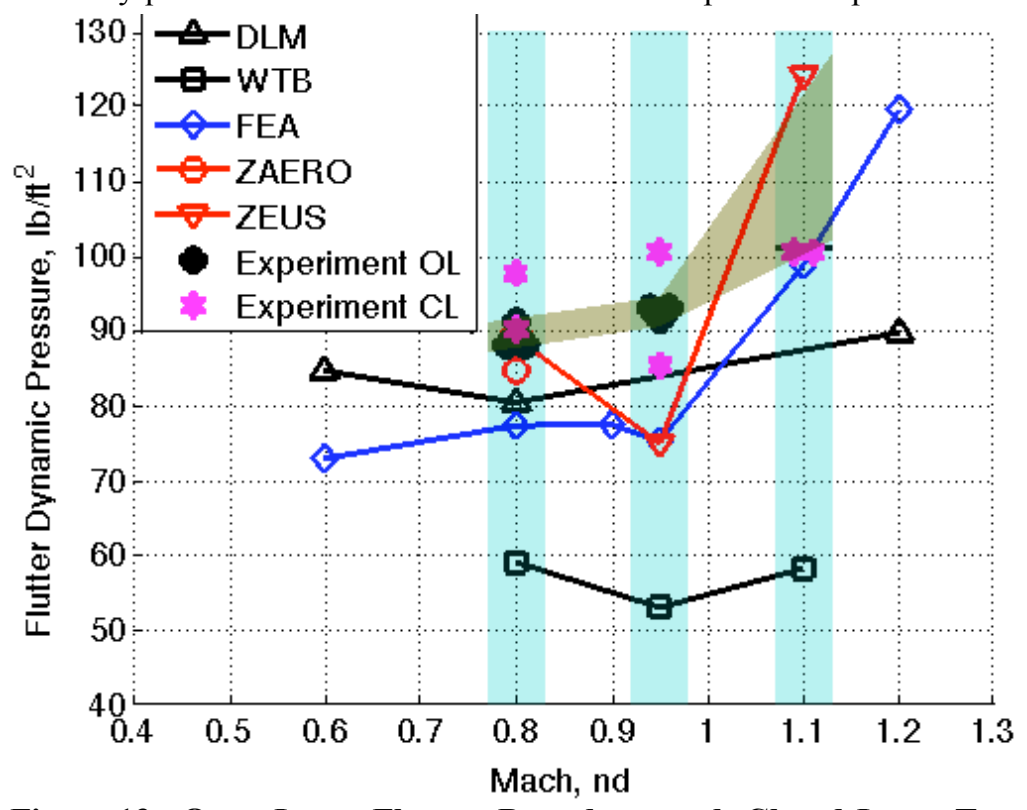

Figure 13. Open-Loop Flutter Boundary and Closed-Loop Test Points. Dynamic pressure at which instability first occurs for analytical plants and as estimated from experimental data, along with highest dynamic pressures tested closed-loop.

\section{Concluding Remarks}

Several objectives were accomplished through development and testing of control laws for the $\mathrm{S}^{4} \mathrm{~T}$ for the third and fourth wind tunnel tests. Analytical models and a Simulink simulation based on those models were developed for use in control law design and evaluation. Metrics were developed for evaluating the Ride Quality Enhancement (RQE) and Gust Load Alleviation (GLA) performance of the control laws. Both SISO and MIMO control laws were

Table 5. Highest Dynamic Pressure Tested

\begin{tabular}{|c|c|c|c|c|}
\hline $\begin{array}{c}\text { Mach } \\
\text { No. }\end{array}$ & $\begin{array}{c}\text { Control } \\
\text { Law }\end{array}$ & $\begin{array}{c}\text { OL } \\
\text { Qf }\end{array}$ & $\begin{array}{c}\text { Highest } \\
\text { Q }\end{array}$ & \% Qf \\
\hline 0.80 & CL121 & 88 & 90.2 & +2.5 \\
\hline 0.80 & v16 & 88 & 97.7 & +11.0 \\
\hline 0.95 & CL221 & 92 & 85.3 & -7.3 \\
\hline 0.95 & v448 & 92 & 100.5 & +9.2 \\
\hline 1.10 & CL321 & $>101$ & 100.4 & N/A \\
\hline 1.10 & s884 & $>101$ & 100.4 & N/A \\
\hline
\end{tabular}
tested safely both below and above the open-loop flutter boundary, due in large part to the use of Controller Performance Evaluation (CPE) software that was able to assess in near real time whether control laws would have adequate stability margins to proceed with testing, based on time history data obtained open- or closed-loop. The experimental open-loop flutter boundary was bracketed from closed-loop testing above and below the open-loop flutter boundary for Mach numbers 0.8 and 0.95 , helping to refine estimates of the open-loop flutter boundary. Control laws were developed and successfully tested above the open-loop flutter boundary, at dynamic pressures $11 \%$ above $\mathrm{Q}_{\mathrm{f}}$ for Mach number 0.8 , and $9.2 \%$ above $\mathrm{Q}_{\mathrm{f}}$ for the Mach number 0.95 test conditions. A lower bound on the open-loop flutter boundary was established for Mach number 1.1, limited operationally by the open-loop flutter boundary at the Mach number 0.95 test condition.

Active controls will likely continue to be of interest for supersonic transport class vehicles due to the need for light weight, high slenderness ratio, and thin wings, and a desire to not penalize the primary supersonic cruise design condition by secondary design conditions such as subsonic cruise over land, or off-design conditions such as transition through the transonic regime at altitudes below supersonic cruise altitude. The $\mathrm{S}^{4} \mathrm{~T}$ active controls testing helps to characterize that application. However, the active controls testing may also help establish an experience

15

American Institute of Aeronautics and Astronautics 
base for applications such as high performance light weight long endurance drones that could implement active controls technology without the same level of certification required for aircraft that have pilots and passengers.

Although the $\mathrm{S}^{4} \mathrm{~T}$ wind-tunnel test program has concluded, the analytical models, simulation, and experimental time history data that were acquired could serve as resources for further studies. One of the biggest challenges with the CPE analysis is being able to extract clean frequency response estimates from time histories that contain the effects of model response to turbulence. The simulation provides a means to evaluate the effectiveness of various excitation signals and signal processing techniques when working with known analytical plant models and having the ability to dial in or out the strength of the simulated turbulence environment. ${ }^{16}$ Improved excitation and signal processing techniques could used for improved online system identification for aeroelastic systems.

\section{References}

${ }^{1}$ Silva, W.A., Perry, B., III, Florance, J.R., Sanetrik, M.D., Wieseman, C.D., Stevens, W.L., Funk, C.F., Hur, J., Christhilf, D.M. and Coulson, D.A., "An Overview of the Semi-Span Super-Sonic Transport $\left(\mathrm{S}^{4} \mathrm{~T}\right)$ Wind-Tunnel Model Program," 53 ${ }^{\text {rd }}$ AIAA/ASME/ASCE/AHS/ASC Structures, Structural Dynamics, and Materials Conference, Honolulu, HI, 2012 (submitted for publication).

${ }^{2}$ Silva, W.A., Perry, B., III, Florance, J.R., Sanetrik, M.D., Wieseman, C.D., Stevens, W.L., Funk, C.F., Hur, J., Christhilf, D.M. and Coulson, D.A., "A Summary of Computational and Experimental Results for the Semi-Span Super-Sonic Transport $\left(\mathrm{S}^{4} \mathrm{~T}\right)$ Wind-Tunnel Model" International Forum of Aeroelasticity and Structural Dynamics, IFASD-2011-147, Paris, France, 2011.

${ }^{3}$ Perry, B., III, Silva, W.A., Florance, J.R., Wieseman, C.D., Pototzky, A.S., Sanetrik, M.D., Scott, R.C., Keller, D.F., Cole, S.R. and Coulson, D.A., "Plans and Status of Wind-Tunnel Testing Employing an Aeroservoelastic Semispan Model," $48^{\text {th }}$ AIAA/ASME/ASCE/AHS/ASC Structures, Structural Dynamics, and Materials Conference, AIAA-2007-1770, Honolulu, HI, 2007.

${ }^{4}$ Schmidt, D.K. and Raney, D.L., "Modeling and Simulation of Flexible Flight Vehicles," J. Guidance, Control, and Dynamics, Vol. 24, No. 3, May-June 2001.

${ }^{5}$ Florance, J.R., "Semi-Span Super-Sonic Transport $\left(\mathrm{S}^{4} \mathrm{~T}\right) \quad$ Wind-Tunnel Model Construction," 53 ${ }^{\text {rd }}$ AIAA/ASME/ASCE/AHS/ASC Structures, Structural Dynamics, and Materials Conference, Honolulu, HI, 2012 (submitted for publication).

${ }^{6}$ Christhilf, D.M., Pototzky, A.S. and Stevens, W.L., "Incorporation of SemiSpan SuperSonic Transport ( ${ }^{4} \mathrm{~T}$ ) Aeroservoelastic Models into SAREC-ASV Simulation," AIAA Modeling and Simulation Technologies Conference, AIAA-2010-8099, Toronto, Ontario, Canada, 2010.

${ }^{7}$ Pototzky, A.S., "Enhanced Modeling of First-Order Plant Equations of Motion for Aeroelastic and Aeroservoelastic Applications," AIAA Atmospheric Flight Mechanics Conference, AIAA-2010-7801, Toronto, Ontario, Canada, 2010.

${ }^{8}$ Sanetrik, M.D., Silva, W.A. and Hur, J., "Computational Aeroelastic Analysis of the Semi-Span Super-Sonic Transport $\left(\mathrm{S}^{4} \mathrm{~T}\right)$ Wind-Tunnel Model," 53 ${ }^{\text {rd }}$ AIAA/ASME/ASCE/AHS/ASC Structures, Structural Dynamics, and Materials Conference, Honolulu, HI, 2012 (submitted for publication).

${ }^{9}$ Moulin, B., Ritz, E., Chen, P.C., Lee, D.H. and Zhang, Z., "CFD-based Control for Flutter Suppression, Gust Load Alleviation, and Ride Quality Enhancement for the $\mathrm{S}^{4} \mathrm{~T}$ Model," AIAA Structures, Structural Dynamics, and Materials Conference, AIAA-2010-2623, Orlando, FL, 2010.

${ }^{10}$ Chen, P. C., Moulin, B., Ritz, E., Lee, D. H., and Zhang, Z., "CFD-based Aeroservoelastic Control for Supersonic Flutter Suppression, Gust Load Alleviation, and Ride Quality Enhancement," AIAA Structures, Structural Dynamics, and Materials Conference, AIAA-2009-2537, Palm Springs, CA, 2009.

${ }^{11}$ Roughen, K.M. and Bendiksen, O.O., "Active Flutter Suppression of the Supersonic Semispan Transport (S $\left.{ }^{4} \mathrm{~T}\right) \mathrm{Model}$," AIAA Structures, Structural Dynamics, and Materials Conference, AIAA-2010-2621, Orlando, FL, 2010.

${ }^{12}$ Roughen, K.M., Bendiksen, O. and Gradient, R., "Active Aeroelastic Control of the Supersonic Semispan Transport ( $\left.\mathrm{S}^{4} \mathrm{~T}\right)$ Model," AIAA Guidance, Navigation and Control Conference, AIAA-2010-8397, Toronto, Ontario, Canada, 2010.

${ }^{13}$ Moulin, B., Ritz, E., Florance, J.R., Sanetrik, M.D. and Silva, W.A., "CFD-based Classic and Robust Aeroservoelastic Control for the SuperSonic SemiSpan Transport Wind-Tunnel Model," AIAA Atmospheric Flight Mechanics Conference, AIAA-2010-7802, Toronto, Ontario, Canada, 2010.

${ }^{14}$ Raymer, D.P., Aircraft Design: A Conceptual Approach, $2^{\text {nd }}$ printing, AIAA, 370 L'Enfant Promenade, S.W., Washington, D.C., 1989, Chapt. 4.

${ }^{15}$ Wieseman, C.D. and Christhilf, D.M., "Analytical and Experimental Evaluation of Digital Control Systems for the SemiSpan Super-Sonic Transport $\left(\mathrm{S}^{4} \mathrm{~T}\right)$ Wind-Tunnel Model," $53^{\text {rd }}$ AIAA/ASME/ASCE/AHS/ASC Structures, Structural Dynamics, and Materials Conference, Honolulu, HI, 2012 (submitted for publication).

${ }^{16}$ Heeg, J. and Wieseman, C.D., "System Identification and Uncertainty Quantification Using Orthogonal Excitations and the Semi-Span Super-Sonic Transport $\left(\mathrm{S}^{4} \mathrm{~T}\right)$ Model," 53 ${ }^{\text {rd }}$ AIAA/ASME/ASCE/AHS/ASC Structures, Structural Dynamics, and Materials Conference, Honolulu, HI, 2012 (submitted for publication). 